\title{
Estudos
}

\section{O Ensino Superior Agrícola no Brasil}

\author{
Guy Capdeville
}

Universidade Federal de Viçosa (UFV)

Historia o surgimento e a evolução do ensino superior agrícola no Brasil. Em 15 de fevereiro de 1877, instalava-se, no Brasil, o primeiro curso superior da área de ciências agrárias - o Curso de Agronomia da Imperial Escola Agrícola da Bahia. Dessa data até 1910 - ano em que se faz a primeira regulamentação oficial desse tipo de ensino - funcionaram, no Brasil, oito cursos de Agronomia. Embora os estatutos da Imperial Escola Agrícola da Bahia (1875) previssem, no seu Art. 50, além do curso de Agronomia, os cursos superiores de Engenharia Agricola, Silvicultura e Veterinária, o primeiro curso de Medicina Veterinária só foi inaugurado em 1913, no Rio de Janeiro. Em 1960, criou-se o primeiro curso de Engenharia Florestal (Viçosa-MG); em 1966, o primeiro de Zootecnia (Uruguaiana-RS) e, em 1973, o primeiro de Engenharia Agrícola (Pelotas-RS). Em janeiro de 1990, eram 72 os cursos de Agronomia; os de Veterinária, 43; os de Engenharia Florestal, 14; os de Zootecnia, 16; e os de Engenharia Agrícola, 8. Em março de 1961, foi inaugurado, na então Universidade Rural do Estado de Minas Gerais, hoje Universidade Federal de Viçosa, o primeiro curso de pós-graduação, no Brasil, no modelo norteamericano do Master of Science ou Magister Scientia?. Em janeiro de 1990, havia 108 cursos de mestrado e 28 de doutorado em Ciências Agrárias, no Brasil. Acredita-se que a formação de profissionais agrícolas de nível superior é uma das áreas bem sucedidas da educação brasileira.

\section{Primórdios}

As primeiras tentativas de se instalar o ensino superior agrícola no Brasil enfrentaram a indiferença das elites e o desinteresse da população. A agricultura nacional, baseada no latifúndio, na monocultura de exportação, no trabalho escravo, na

R. bras. Est. pedag., Brasília, v.72, n.172, p.229-2Gl, set./dez. 1991 
abundância de terras novas e férteis e no descaso pelo manejo e conservação do solo, exigia muito pouca diversificação e quase nenhuma qualificação da força de trabalho. Segue-se daí que nenhum serviço a escola tinha a lhe prestar, no que se refere à formação de mão-de-obra. Quanto à reprodução das relações de dominação e da ideologia dominante, outras agências dela se encarregavam, satisfatoriamente (Freitag, 1986, p.45 e 48).

Não havia, pois, razões para o governo criar escolas agrícolas, nem mesmo outra escola qualquer, no campo. A agricultura, praticada por escravos e ex-escravos, não era exercida "profissionalmente". O campesinato surgiu muito tarde, no Brasil. O trabalho assalariado na agricultura só começou a ser realmente praticado após a chegada dos imigrantes europeus, que vieram substituir o trabalho escravo. Os imigrantes, de sua parte, também não precisavam de mais educação do que a que já possuíam, para o desempenho das atividades que lhes eram confiadas. A atividade agrícola era, deste modo, considerada um ofício para o qual não se precisa de treinamento algum. Qualquer um poderia exercê-lo; daí seu desprestígio. Esse ofício não envolvia perícia técnica que precisasse ser aprendida, e é justamente por isso que qualquer um poderia exercê-lo. Para que estudá-lo, então?

Outras, portanto, foram as razões que levaram, primeiramente, Dom João e, depois, os outros que seguiram seu exemplo a se preocuparem com "escolas de agricultura"; provavelmente a inspiração do Príncipe Regente veio dos ideais iluministas em que fora educado, combinados com a necessidade bem prática e imediata de adaptar o país à sua nova condição de sede da Corte Portuguesa.

Entretanto, nem mesmo o empenho de Dom João e, posteriormente, o daqueles que o imitaram conseguiram vencer a inércia da desmotivação e do desinteresse por este tipo de estudo. Quando, em 1859, se propôs a fundação da Escola Superior Agrícola da Bahia, destinada à formação de "agrônomos, engenheiros agrícolas, silvicultores e veterinários", deu-se o mesmo fenômeno. Todos aceitavam a importância e a oportunidade da idéia de se criar uma escola agrícola superior, não porém com o entusiasmo 
suficiente para colocá-la em prática. A escola da Bahia levou 17 anos para passar de ideal a realidade e, quando o fez, não foi sem tropeços. A primeira turma de formados, em 1880, foi de dez alunos, mas nos cinco anos seguintes a média de formados foi de 4,5 por ano. Ao apagar das luzes do século XIX, a matrícula caiu praticamente para zero e, no início do século XX (1902), a escola foi fechada.

A situação da segunda escola superior agrícola, a de Pelotas, no Rio Grande do Sul, não foi mais animadora. Nos seus primeiros 20 anos de funcionamento, a média de formados foi de apenas um por ano (Tabela 1). Para aumentar o número de matrículas, sugeria-se recrutar os alunos nos "estabelecimentos pios". O governo, por outro lado, só após muito relutar, concorda em aprovar os regulamentos dessas escolas, mas se recusa sempre a lhes conceder recursos, que alega não possuir, o que é verdade, pois suas opções de gastos são sempre outras.

Em São Paulo, quando houve problemas com a lavoura cafeeira, tais como escassez de mão-de-obra, insuficiência de crédito e problemas fitossanitários, não se pensou em abrir uma escola para formar profissionais habilitados, mas preferiu-se abrir uma Estação Agronômica para melhoramento de sementes, introdução de novas máquinas e combate às pragas. Sem a menor cerimônia, o ministro da Agricultura paralisou, em 1885, as obras da escola de Pelotas e transferiu os recursos para a construção da Estação Agronômica de Campinas, segundo relatou Crespo (1894). Em Piracicaba, alguns anos mais tarde, Luiz de Queiroz viu-se obrigado a empreender sozinho a construção da escola que recebeu seu nome, porque não encontrou uma pessoa sequer que estivesse disposta a colaborar em seu projeto. Quando entregou a obra, inacabada, em doação, ao Estado, gravou-a com uma cláusula de reversão da propriedade ao doador ou a seus herdeiros, caso o Estado não colocasse a escola em funcionamento dentro de dez anos. Por pouco, o prazo não venceu e a escola não voltou aos herdeiros de Luiz de Queiroz.

Outros cursos, porém, tiveram uma sorte mais adversa ainda. O curso da Escola de Engenharia de Porto Alegre subsistiu 
Tabela 1 - Número de formados, por ano, nas 10 mais antigas Escolas de Agronomia do Pais (1877-1989)

\begin{tabular}{|c|c|c|c|c|c|c|c|c|c|c|}
\hline $\begin{array}{l}\text { INST } \\
\text { ANOS } \\
\end{array}$ & UFBA & UFPEL & ESALQ & ESAL & UFRGS & UFRRJ & UFRPE & UFPR & UFCE & $\mathrm{UFV}$ \\
\hline 1877 & 0 & - & - & - & - & & & - & - & \\
\hline 1878 & 0 & - & - & - & - & & & - & - & - \\
\hline 1879 & 10 & - & - & - & & & & & - & - \\
\hline 1880 & 2 & - & - & - & - & & & - & - & - \\
\hline 1881 & 5 & - & - & - & - & & & - & - & - \\
\hline 1882 & 6 & - & - & - & & & - & - & - & - \\
\hline 1883 & 3 & - & - & - & & & & - & - & - \\
\hline 1884 & 6 & - & - & - & & & - & - & - & - \\
\hline 1885 & 13 & - & - & - & & & & & & - \\
\hline 1886 & 14 & - & - & - & & & & - & - & - \\
\hline 1887 & 6 & - & - & & & & & & & - \\
\hline $\begin{array}{l}1889 \\
1890\end{array}$ & $\begin{array}{l}9 \\
9\end{array}$ & - & - & - & & & - & - & - & - \\
\hline 1891 & 15 & $\overline{0}$ & - & & & & & - & - & - \\
\hline 1892 & 13 & 0 & - & & & & & - & - & - \\
\hline 1893 & 6 & 0 & - & & - & - & - & - & - & - \\
\hline 1894 & 8 & 0 & - & & & - & - & - & - & - \\
\hline 1895 & 19 & 0 & & & & - & - & - & - & - \\
\hline 1896 & 37 & 0 & & & & - & - & - & - & - \\
\hline 1897 & 15 & 0 & - & & - & - & - & - & - & - \\
\hline 1898 & 28 & 0 & & & & - & - & - & - & - \\
\hline 1899 & 15 & 0 & - & - & - & - & - & - & - & - \\
\hline 1900 & 10 & 2 & $\overline{0}$ & - & - & - & - & - & - & - \\
\hline 1901 & 10 & 1 & 0 & - & - & - & - & - & - & - \\
\hline 1902 & 5 & 0 & 0 & & - & - & - & - & - & - \\
\hline 1903 & 0 & 3 & 7 & - & - & - & - & - & - & - \\
\hline 1904 & 9 & 2 & 5 & - & - & - & - & - & - & - \\
\hline 1905 & 0 & 1 & 7 & - & - & - & - & - & - & - \\
\hline 1906 & 0 & 0 & 3 & '- & - & - & - & - & - & - \\
\hline 1907 & 0 & 0 & 5 & - & - & - & - & - & - & - \\
\hline 1908 & 0 & 0 & 11 & 0 & - & - & - & - & - & - \\
\hline 1909 & 0 & 7 & 22 & 0 & - & - & - & - & - & - \\
\hline 1910 & 0 & 2 & 14 & 0 & - & - & - & - & - & - \\
\hline 1911 & 0 & 7 & 27 & 3 & 0 & - & - & - & - & - \\
\hline 1912 & 0 & 6 & 31 & 3 & 0 & - & - & - & - & - \\
\hline 1913 & 0 & 6 & 33 & 1 & 0 & 0 & - & - & - & - \\
\hline 1914 & 15 & 12 & 23 & 4 & 4 & 27 & 0 & - & - & - \\
\hline 1915 & 0 & 9 & 41 & 6 & 10 & 29 & 0 & - & - & - \\
\hline 1916 & 0 & 10 & 33 & 4 & 21 & 2 & 1 & - & - & - \\
\hline 1917 & 0 & 5 & 24 & 5 & 8 & 10 & 10 & - & - & - \\
\hline 1918 & 0 & 0 & 17 & 3 & 9 & 5 & 10 & 0 & 0 & - \\
\hline 1919 & 0 & 12 & 3 & 8 & 6 & 14 & 4 & 0 & 0 & - \\
\hline 1920 & 0 & 2 & 22 & 5 & 3 & 14 & 11 & 44 & 0 & - \\
\hline 1921 & 0 & 3 & 20 & 0 & 2 & 15 & 0 & 5 & 30 & - \\
\hline 1922 & 0 & 6 & 13 & 9 & 0 & 10 & 1 & 9 & 9 & - \\
\hline 1923 & 22 & 2 & 10 & 5 & 12 & 8 & 9 & 11 & 11 & - \\
\hline 1924 & 8 & 3 & 12 & 2 & 0 & 13 & 9 & 5 & 10 & - \\
\hline 1925 & 4 & 3 & 16 & 6 & 5 & 12 & 3 & 8 & 6 & - \\
\hline 1926 & 7 & 4 & 9 & 6 & 5 & 12 & 0 & 2 & 3 & - \\
\hline 1927 & 4 & 4 & 15 & 2 & 7 & 3 & 6 & 6 & 3 & - \\
\hline 1928 & 6 & 1 & 16 & 3 & 8 & 1 & 4 & 6 & 2 & 0 \\
\hline 1929 & 8 & 1 & 16 & 3 & 7 & 6 & 1 & 1 & 2 & 0 \\
\hline
\end{tabular}


(continuação)

\begin{tabular}{|c|c|c|c|c|c|c|c|c|c|c|}
\hline $\begin{array}{l}\text { INST } \\
\text { ANOS }\end{array}$ & UFBA & UFPEL & ESALQ & ESAL & UFRGS & UFRRJ & UFPE & UFPR & UFCE & UFV \\
\hline 1930 & 13 & 2 & 21 & 4 & 6 & 3 & 6 & 4 & 2 & 0 \\
\hline 1931 & 18 & 3 & 12 & 2 & 2 & 8 & 2 & 2 & 3 & 7 \\
\hline 1932 & 7 & 5 & 22 & 5 & 2 & 6 & $1 \overline{1}$ & 4 & 0 & 7 \\
\hline 1933 & 57 & 2 & 19 & 5 & 3 & 15 & 3 & 3 & 6 & 8 \\
\hline 1934 & 0 & 5 & 22 & 5 & 2 & 12 & 10 & 1 & 3 & 12 \\
\hline 1935 & 13 & 4 & 39 & 15 & 2 & 17 & 12 & 6 & 17 & 16 \\
\hline 1936 & 13 & 2 & 25 & 2 & 3 & 7 & 11 & 8 & 3 & 12 \\
\hline 1937 & 27 & 4 & 48 & 16 & 2 & 14 & 21 & 4 & 28 & 23 \\
\hline 1938 & 42 & 1 & 42 & 8 & 4 & 10 & 17 & 11 & 25 & 15 \\
\hline 1939 & 25 & 6 & 17 & 10 & 12 & 21 & 17 & 12 & 37 & 10 \\
\hline 1940 & 23 & 4 & 39 & 16 & 0 & 20 & 13 & 25 & 24 & 11 \\
\hline 1941 & 20 & 0 & 54 & 6 & 1 & 10 & 5 & 12 & 6 & 9 \\
\hline 1942 & 15 & 1 & 56 & 6 & 4 & 20 & 2 & 3 & 11 & 17 \\
\hline 1943 & 8 & 0 & 64 & 22 & 4 & 24 & 19 & 19 & 13 & 16 \\
\hline 1944 & 3 & 13 & 54 & 15 & 8 & 30 & 22 & 17 & 12 & 9 \\
\hline 1945 & 9 & 18 & 60 & 14 & 9 & 28 & 22 & 15 & 14 & 9 \\
\hline 1946 & 15 & 6 & 54 & 16 & 15 & 25 & 24 & 12 & 3 & 20 \\
\hline 1947 & 18 & 10 & 74 & 13 & 17 & 34 & 35 & 7 & 10 & 23 \\
\hline 1948 & 24 & 11 & 73 & 12 & 20 & 39 & 40 & 10 & 13 & 13 \\
\hline 1949 & 24 & 15 & 58 & 11 & 14 & 37 & 21 & 9 & 9 & 20 \\
\hline 1950 & 16 & 16 & 36 & 6 & 28 & 28 & 6 & 14 & 18 & 18 \\
\hline 1951 & 15 & 15 & 39 & 14 & 28 & 58 & 12 & 23 & 12 & 17 \\
\hline 1952 & 14 & 23 & 54 & 15 & 28 & 68 & 14 & 29 & 15 & 20 \\
\hline 1953 & $\begin{array}{l}14 \\
10\end{array}$ & 17 & 56 & 8 & 36 & 35 & $\begin{array}{l}14 \\
15\end{array}$ & 22 & 11 & 14 \\
\hline 1954 & 5 & 13 & 74 & 17 & 25 & 31 & 19 & 15 & 9 & 32 \\
\hline 1955 & 12 & 3 & 51 & 13 & 25 & 54 & 19 & 35 & 13 & 33 \\
\hline 1956 & 15 & 7 & 59 & 11 & 34 & 34 & 12 & 13 & 14 & 19 \\
\hline 1957 & 14 & 11 & 69 & 12 & 30 & 39 & 21 & 29 & 12 & 12 \\
\hline 1958 & 14 & 17 & 91 & 19 & 43 & 48 & 19 & 14 & 17 & 28 \\
\hline 1959 & 23 & 8 & 57 & 15 & 40 & 43 & 34 & 23 & 24 & 24 \\
\hline 1960 & 17 & 14 & 73 & 13 & 40 & 50 & 32 & 22 & 30 & 35 \\
\hline 1961 & 20 & 22 & 99 & 29 & 34 & 47 & 28 & 27 & 32 & 47 \\
\hline 1962 & 25 & 29 & 5 & 31 & 49 & 44 & 27 & 28 & 49 & 61 \\
\hline 1963 & 24 & 43 & 66 & 20 & 50 & 47 & 17 & 24 & 58 & 79 \\
\hline 1964 & 39 & 34 & 86 & 23 & 78 & 67 & 31 & 30 & 48 & 80 \\
\hline 1965 & 40 & 58 & 119 & 17 & 64 & 94 & 34 & 41 & 51 & 86 \\
\hline 1966 & 38 & 53 & 152 & 24 & 65 & 137 & 57 & 57 & 70 & 82 \\
\hline 1967 & 56 & 63 & 197 & 30 & 67 & 164 & 89 & 74 & 80 & 56 \\
\hline 1968 & 63 & 58 & 204 & 33 & 63 & 87 & 76 & 81 & 100 & 93 \\
\hline 1969 & 40 & 68 & 200 & 35 & 70 & 99 & 76 & 83 & 131 & 120 \\
\hline 1970 & 48 & 69 & 184 & 45 & 80 & 91 & 51 & 99 & 144 & 101 \\
\hline 1971 & 56 & 84 & 216 & 52 & 69 & 61 & 45 & 114 & 128 & 104 \\
\hline 1972 & 80 & 94 & 188 & 74 & 44 & 93 & 54 & 128 & 125 & 134 \\
\hline 1973 & 80 & 107 & 351 & 61 & 43 & 80 & 91 & 126 & 117 & 137 \\
\hline 1974 & 9 & 76 & 147 & 104 & 65 & 122 & 60 & 121 & 117 & 145 \\
\hline 1975 & 13 & 159 & 192 & 121 & 74 & 118 & 39 & 99 & 113 & 154 \\
\hline 1976 & 68 & 133 & 192 & 122 & 71 & 127 & 119 & 76 & 125 & 151 \\
\hline 1977 & 135 & 126 & 196 & 89 & 68 & 112 & 146 & 81 & 116 & 148 \\
\hline 1978 & 61 & 126 & 182 & 115 & 62 & 108 & 128 & 110 & 108 & 98 \\
\hline 1979 & 129 & 117 & 196 & 121 & 33 & 128 & 119 & 59 & 51 & 117 \\
\hline 1980 & 140 & 92 & 194 & 115 & 50 & 138 & 149 & 119 & 85 & 112 \\
\hline 1981 & 76 & 119 & 202 & 116 & 52 & 157 & 163 & 76 & 130 & 107 \\
\hline 1982 & 88 & 139 & 187 & 150 & 63 & 125 & 104 & 104 & 106 & 169 \\
\hline 1983 & 109 & 169 & 190 & 133 & 66 & 115 & 124 & 122 & 114 & 192 \\
\hline 1984 & 178 & 149 & 169 & 139 & 66 & 115 & 136 & 92 & 57 & 201 \\
\hline 1985 & 112 & 147 & 201 & 186 & 66 & 117 & 104 & 104 & 134 & 207 \\
\hline 1986 & $\begin{array}{l}112 \\
108\end{array}$ & \begin{tabular}{|l|}
147 \\
134
\end{tabular} & $\begin{array}{l}201 \\
152\end{array}$ & \begin{tabular}{|l|}
100 \\
194
\end{tabular} & 76 & 121 & \begin{tabular}{|l|}
104 \\
142
\end{tabular} & \begin{tabular}{|l|}
104 \\
132
\end{tabular} & $\begin{array}{l}134 \\
102\end{array}$ & 207 \\
\hline 1987 & 53 & 135 & 178 & 193 & 76 & 85 & 92 & 93 & 143 & 121 \\
\hline
\end{tabular}

R. bras. Est. pedag., Brasília, v.72, n.172, p.229-261, set/dez. 1991 
(enutżoos)

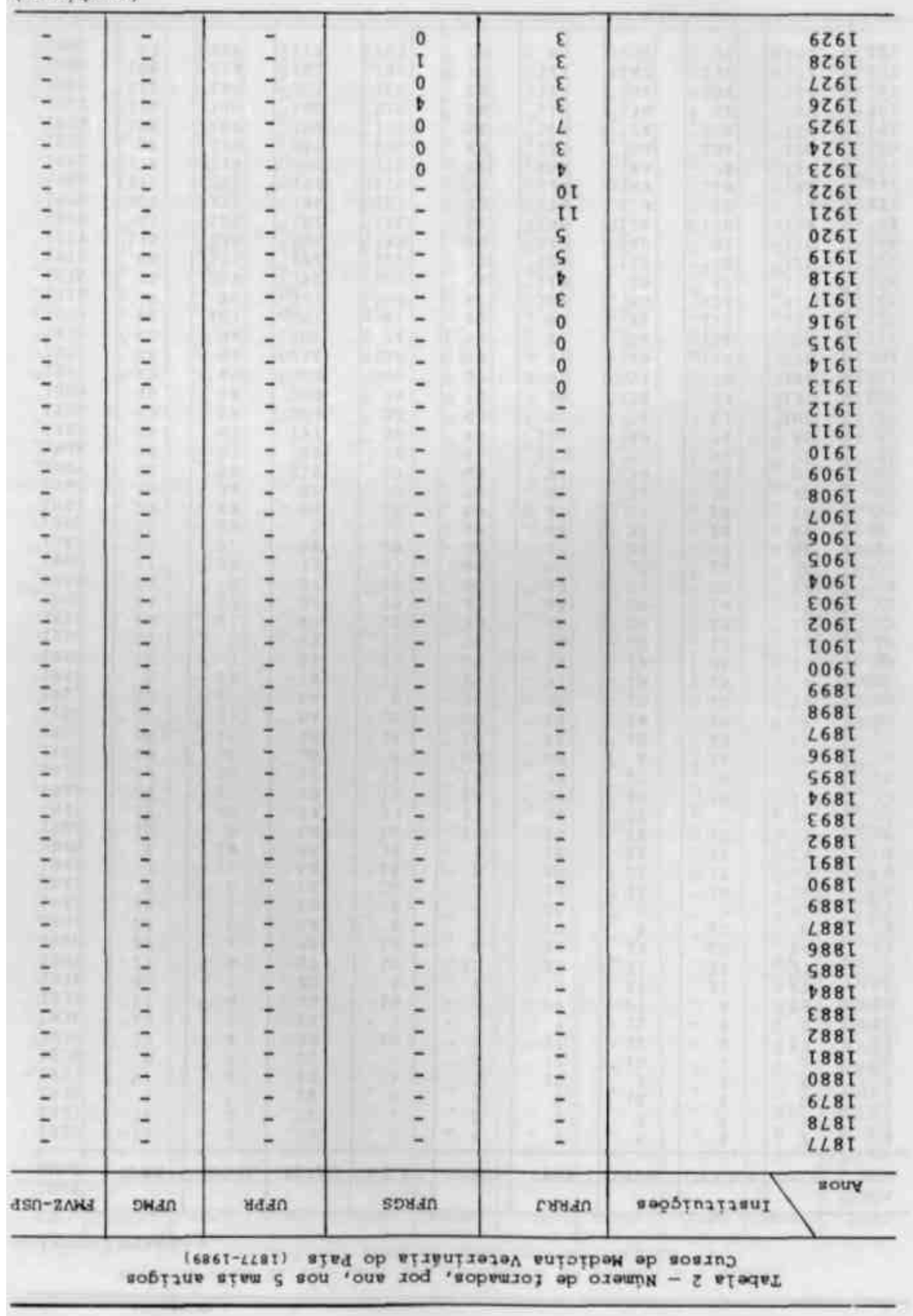


(continuação)

\begin{tabular}{|c|c|c|c|c|c|}
\hline $\begin{array}{l}\text { Instituições } \\
\text { Anos }\end{array}$ & UFRRJ & UFRGS & UFPR & UFMG & FMVZ-USP \\
\hline $\begin{array}{l}1930 \\
1931 \\
1932 \\
1933 \\
1934 \\
1935 \\
1936 \\
1937 \\
1938 \\
1939 \\
1940 \\
1941 \\
1942 \\
1943 \\
1944 \\
1945 \\
1946 \\
1947 \\
1948 \\
1949 \\
1950 \\
1951 \\
1952 \\
1953 \\
1954 \\
1955 \\
1956 \\
1957 \\
1958 \\
1959 \\
1960 \\
1961 \\
1962 \\
1963 \\
1964 \\
1965 \\
1966 \\
1967 \\
1968 \\
1969 \\
1970 \\
1971 \\
1972 \\
1973 \\
1974 \\
1975 \\
1976 \\
1977 \\
1978 \\
1979 \\
1980 \\
1981 \\
1982 \\
1983 \\
1984 \\
1985 \\
1986 \\
1987\end{array}$ & $\begin{array}{r}11 \\
7 \\
10 \\
21 \\
16 \\
30 \\
13 \\
18 \\
82 \\
9 \\
11 \\
16 \\
11 \\
16 \\
16 \\
9 \\
4 \\
6 \\
27 \\
15 \\
16 \\
14 \\
16 \\
23 \\
15 \\
25 \\
25 \\
31 \\
37 \\
33 \\
42 \\
42 \\
44 \\
39 \\
31 \\
37 \\
39 \\
78 \\
60 \\
23 \\
67 \\
47 \\
85 \\
52 \\
85 \\
69 \\
98 \\
137 \\
52 \\
96 \\
95 \\
112 \\
141 \\
112 \\
106 \\
112 \\
116 \\
125\end{array}$ & $\begin{array}{r}0 \\
0 \\
1 \\
0 \\
0 \\
0 \\
9 \\
5 \\
4 \\
6 \\
19 \\
14 \\
14 \\
28 \\
20 \\
6 \\
6 \\
6 \\
6 \\
6 \\
13 \\
7 \\
7 \\
6 \\
12 \\
9 \\
17 \\
12 \\
10 \\
10 \\
12 \\
16\end{array}$ & $\begin{array}{r}0 \\
0 \\
0 \\
0 \\
6 \\
4 \\
4 \\
3 \\
3 \\
4\end{array}$ & $\begin{array}{r}\cdot \\
0 \\
0 \\
0 \\
4 \\
3 \\
7 \\
8 \\
9 \\
7 \\
0 \\
0 \\
13 \\
7 \\
8 \\
5 \\
6 \\
9 \\
5 \\
12 \\
8 \\
15 \\
13 \\
21 \\
13 \\
17 \\
17 \\
16 \\
14 \\
18 \\
33 \\
23 \\
21 \\
24 \\
43 \\
41 \\
25 \\
52 \\
44 \\
26 \\
91 \\
93 \\
69 \\
112 \\
109 \\
118 \\
141 \\
139 \\
109 \\
104 \\
102 \\
114 \\
92 \\
54 \\
88 \\
111 \\
112\end{array}$ & $\begin{array}{r}- \\
- \\
- \\
0 \\
0 \\
0 \\
0 \\
9 \\
13 \\
6 \\
5 \\
2 \\
9 \\
7 \\
13 \\
7 \\
18 \\
9 \\
15 \\
11 \\
12 \\
21 \\
16 \\
12 \\
25 \\
18 \\
22 \\
5 \\
23 \\
16 \\
30 \\
21 \\
16 \\
27 \\
34 \\
36 \\
29 \\
23 \\
61 \\
69 \\
\star \\
53 \\
69 \\
63 \\
81 \\
88 \\
75 \\
106 \\
116 \\
100 \\
88 \\
80 \\
87 \\
77 \\
84 \\
71 \\
80\end{array}$ \\
\hline
\end{tabular}

R. bras. Est. pedag., Brasília, v.72, n.172, p.229-261, set./dez. 1991 
só por causa da providencial interveniência do governo federal, que aplicou a ele o disposto no Decreto $\mathrm{n}^{9} 8.319$, de 20 de outubro de 1910, que ordenava a criação de uma escola média ou teórico-prática de agricultura no sul do país (Capdeville, 1989).

As iniciativas de se criarem os primeiros cursos agrícolas de nível superior no Brasil foram, por outro lado, atos isolados, esparsos e distanciados, uns dos outros, no tempo e no espaço. Além disto, o desempenho inicial dessas escolas e cursos, via de regra, foi muito ruim. A metade dos cursos acabou sendo extinta antes de 1910, e o número de profissionais por eles formados foi muito pequeno. A dispersão dessas iniciativas e seus pífios resultados (Tabela 1) repelem as análises e explicações abrangentes que atribuem a criação desses cursos a racionalidades amplas e compreensivas ou a decisões concertadas, capazes de dar conta do surgimento de todos eles. Na realidade, parece ter havido certo espontaneísmo em suas origens: uns, estimulados pelo "espírito esclarecido" de seus fautores; outros, pela sugestão de modelos estrangeiros; outros, até, pela tentativa de encontrar respostas para as necessidades sentidas pela agricultura de sua região. Reforça esta análise o fato de todos eles terem enfrentado sérios problemas para sobreviver, como falta de recursos, indiferença da população, baixo número de alunos e outros. Por isto, só três deles funcionavam em 1910: o de Pelotas-RS (1891), o de Piracicaba-SP (1901) e o de Lavras-MG (1908), e todos eles mourejavam em meio a muitas dificuldades e com pouquíssimos alunos (Capdeville, 1989).

As últimas décadas do século XIX correspondem a um período de transição no país. A interdição do tráfico de escravos em 1850 liberara grande quantidade de capitais que estavam investidos nessa atividade e provocara importante diminuição da remessa de divisas para o exterior. Esses recursos foram imediatamente realocados para outros empreendimentos, produzindo enorme impacto sobre as atividades econômicas, as quais conheceram momentos de grande euforia (Soares, 1977). A segunda metade do século XIX assistiu, então, a uma aceleração da acumulação de capital, com o fortalecimento da burguesia co- 
mercial e financeira. Ao mesmo tempo, o trabalho escravo era substituído pelo trabalho assalariado e a terra se transformava em mercadoria, em objeto de compra e venda. No final do século, ocorrem as primeiras manifestações da Revolução Industrial nos dois centros urbanos, Rio de Janeiro e São Paulo. A agricultura, porém, conservava sua importância para a acumulação capitalista, permitindo a entrada, no país, das divisas que iriam possibilitar a importação de bens de capital. De outro lado, a agricultura supria a indústria, com matéria prima, e os grandes centros urbanos, com alimentos, além de fornecer importantes contingentes de consumidores para os bens industrializados. No entanto, o direcionamento da produção agrícola para a monocultura de gêneros de exportação, a prática do monopólio, a estocagem especulativa de alimentos e outros procedimentos ditados pela ganância e expectativa de lucro rápido logo produziram insuportável carestia dos gêneros alimentícios, dando ensejo à insatisfação popular. Foi neste ambiente que começaram a funcionar os primeiros cursos de Agronomia no Brasil. No entanto, a rigor, nenhum deles pode ser atribuído às circunstâncias que acabam de ser descritas nem há elementos que permitam relacionar o surgimento dos diversos cursos entre si.

\section{O período de 1910 a 1960}

No início do século XX, o Brasil continuava sendo um país eminentemente agrícola que produzia para exportar e que não conseguia suprir a si mesmo com os gêneros alimentícios necessários ao seu abastecimento interno. A guerra de 1914, que proporcionou condição para um surto de industrialização, agravou a situação de desabastecimento e carestia dos gêneros alimentícios, pois orientou mais ainda as atividades agrícolas para a exportação, a fim de abastecer os países em guerra. As camadas populares sofrem, então, mais uma vez, os efeitos do modelo econômico. A burguesia nacional, também atingida pela crise, passa a sugerir o controle dos preços dos produtos alimentícios e que se limitem as exportações, entrando em choque com a oligarquia ru- 
ral. A burguesia interessava que os preços dos gêneros alimentícios se mantivessem baixos, não forçando a alta dos salários. Essas fortes tensões levaram aos movimentos sociais de 1917 e 1918. Nessas circunstâncias, no período de 1901 a 1918, foram criados, no país, 15 cursos de Agronomia, nove dos quais foram extintos. Em 1910, dois dos remanescentes tinham sido criados antes da regulamentação oficial deste tipo de ensino. Dos 13 cursos, portanto, criados entre 1910 e 1918, somente quatro permaneceram até hoje. São eles: o da Rural do Rio de Janeiro, o da Rural de Pernambuco (à época pertencendo aos monges beneditinos), o da Universidade Federal do Paraná e o da Universidade Federal do Ceará (Anexo 1). No mesmo período, foram criados cinco cursos de Veterinária, dos quais apenas um, o da Universidade Federal Rural do Rio de Janeiro, permanece até hoje (Anexo 2). Nas duas primeiras décadas do século XX, apesar do Decreto $n^{8} 8.319$, de 20 de outubro de 1910, que baixou a primeira regulamentação oficial do ensino agrícola no país, o ensino superior agrícola continuava a ser considerado um fator desprezível ou, quando muito, de importância marginal, na política agrária brasileira. Aliás, a educação como um todo, no Brasil, só passará a freqüentar o elenco das preocupações nacionais na terceira década do século XX.

Ao primeiro Código do Ensino Agrícola (1910), centralizador e detalhista, seguiu-se, pouco depois, a Reforma Rivadávia Correa (1911), "desoficializante" e descentralizadora, mas que em nada modificou o ensino agrícola. Quatro anos mais tarde, a Reforma Carlos Maximiliano (1915) busca coibir os excessos da Reforma Rivadávia, reorganizando e reoficializando o ensino. O ensino agrícola, porém, continuou ligado ao Ministério da Agricultura, não sendo atingido pela legislação comum. Dez anos mais tarde, faz-se a Reforma João Luiz Alves, também conhecida como Reforma Rocha Vaz (1925), de forte tendência centralizadora e autoritária, tendência esta confirmada e reforçada, seis anos mais tarde, com a Reforma Francisco Campos, de 1931. Inicia-se, a partir daí, a integração do ensino agrícola ao sistema nacional de educação. Assiste-se, no entanto, 
neste período, a um suceder de leis e decretos desconexos e de reformas contraditórias, embora se observe, a partir de 1925, um caminhar em direção à unificação e à uniformização do ensino. No caso do ensino superior, instituem-se as escolas-modelo ou escolas-padrão e, no ensino médio, promulgam-se as chamadas "leis orgânicas" (1924-1946), que articulam entre si os diversos graus de ensino e seus diversos ramos, estabelecendo currículos obrigatórios para todo o território nacional. Nesse período, aplicam-se ao ensino agrícola, que era considerado um ramo especial de ensino, vários regulamentos do ensino comum.

A partir de 1920 já se procurava estabelecer um sistema nacional de educação. Nunca, até então, se tinha assistido, no país, a tanto interesse pelo problema da educação. A criação da Associação Brasileira de Educação (ABE) em 1922, os inquéritos nacionais sobre a educação, os debates na imprensa e as conferências nacionais de educação foram as manifestações mais explícitas desse interesse. Nunca se legislou tanto sobre educação como no período de 1925 (Reforma Rocha Vaz) a 1946 (Lei Orgânica do Ensino Agrícola - Decreto-Lei no 9.613, de 20 de agosto de 1946). Período de tanto interesse pelo problema da educação só voltará a ocorrer por ocasião da discussão do projeto da Lei de Diretrizes e Bases da Educação Nacional (1948-1961). O entusiasmo com o problema da educação nacional provocou uma farta produção de literatura especializada e o aparecimento da figura do educador profissional.

Em 1930, cria-se o Ministério da Educação e Saúde Pública e, em 1931, o ministro Francisco Campos inicia sua reforma, buscando uma sistematização da educação nacional. Em 1932, o Manifesto dos Pioneiros da Educação Nova estabelece um ideário pedagógico, tendo em vista a Constituição de 1934, que se devia promulgar. O país se transforma. O modelo agrário exportador busca reestruturar-se para sair da crise que, há anos, o sufoca, e a industrialização caminha.

A Constituição de 1946, democrática, reserva um capítulo especial à educação, permite a acumulação de cargo técnico com 
o magistério e determina que o Congresso Nacional estabeleça as diretrizes e bases da educação nacional.

No período de 1918 a 1950, foram criados sete cursos de Agronomia, cinco dos quais estão hoje extintos (Anexo 1). Criaram-se, igualmente, no mesmo período, nove cursos de Medicina Veterinária, quatro dos quais foram extintos (Anexo 2). Dos cursos de Agronomia, só um foi criado pelo Estado, o de Viçosa (pelo Estado de Minas Gerais, em 1922), e, dos cursos de Medicina Veterinária, apenas dois, o de Viçosa e o de São Paulo. Nenhum foi criado pela União, neste intervalo de 32 anos. Aliás, de 1877 a 1950, dos 29 cursos de Agronomia que funcionaram no país, somente um foi criado para ser mantido pela União, o da Rural do Rio de Janeiro. Os de Pinheiros, de Salvador e de Porto Alegre, que se beneficiaram do Decreto $\mathrm{n}^{0} 8.319$, de 20 de outubro de 1910, já existiam e simplesmente foram adaptados ao novo regime. Deles, porém, só permaneceram o da Rural do Rio de Janeiro e o de Porto Alegre, dado que o da Bahia e o de Pinheiros acabaram absorvidos pelo da Rural do Rio de Janeiro (Capdeville, 1989).

Os males da Agricultura, no período, eram diagnosticados como de natureza estritamente econômico-financeira e, por isso, entre os remédios indicados, não se previa a formação de profissionais de nível superior.

A crise da Agricultura nas décadas de 20 e 30, cuja manifestação mais expressiva foi a queima de seu produto maior, o café, para a regulagem dos estoques, com vistas à sustentação dos preços, tinha raízes internacionais, dado que os produtos agrícolas oscilavam ao sabor das crises do mercado internacional. Exemplos sejam as crises de 1913, de 1929 e da $2^{\text {a }}$ Guerra Mundial (1939 - 1945), agravadas internamente pelos problemas de abastecimento e carestia, as quais levaram o governo a medidas que iam desde o incentivo à produção (durante as guerras) até a criação de órgãos de apoio e fomento, como a Delegacia Executiva da Produção Nacional, que atuava junto aos agricultores, criando, por exemplo, a figura dos "agrônomos itinerantes"; ou como o Departamento Nacional do Café e os ins- 
titutos do açúcar e do álcool, do mate, do sal, do pinho, do cacau e outros. Todos esses órgãos precisavam da presença de técnicos habilitados para desempenhar suas funções. No entanto, nos governos de Vargas (19301945), nenhuma medida foi tomada no sentido de formar esses profissionais. Dos cinco cursos de Agronomia criados nesse período (Anexo 1), nenhum o foi pela União. Dois foram criados pelos governos de seus respectivos Estados, o de Barreiros, em Pernambuco, que só funcionou um ano e meio, e o de Areias, na Paraíba, que foi o único dos cinco a subsistir até hoje. No mesmo período, foram criados quatro cursos de Veterinária. Todos eles subsistem até hoje (Anexo 2). Dois deles foram criados por iniciativa particular, o do Paraná (1931) e o de Niterói (1936). Os outros dois foram criados pelos Estados de Minas (Viçosa, em 1932) e de São Paulo (São Paulo, capital, em 1935). A União só virá a se envolver com a formação dos profissionais agrícolas de nível superior a partir de 1950, por meio das "federalizações" (Lei ${ }^{8} 1.055$, de 16 de janeiro de 1950). Inúmeras foram as instituições de ensino superior "federalizadas" em 1950. A então Universidade Rural do Estado de Minas Gerais (UREMG), sediada em Viçosa, chegou a ser "federalizada" pela Lei ${ }^{\circ}$ 1.254 , de 4 de dezembro de 1950. No entanto, a UREMG resistiu à idéia e a "federalização", não se consumou. A Lei $\mathrm{n}^{0} 2.470$, de 28 de abril de 1955, transformou-a, de "instituição federalizada" em "entidade subvencionada" pelo governo federal. Nada indica, no entanto, que esse "interesse" da União pelo ensino superior agrícola tenha a ver com "mudanças" ou novas "necessidades" da agricultura brasileira. Aliás, as "federalizações" não foram privilégios das instituições de ensino superior agrícola. Pelo contrário, elas atingiram todas as áreas, e continuaram na década de 60, surgindo, assim, várias universidades federais. As "federalizações" em grupo, iniciadas no governo Dutra, no entanto, significaram um maior envolvimento da União na formação de profissionais de nível superior, e o setor agrícola foi um dos primeiros que se beneficiaram delas. A decisão do governo federal de realizar as "federalizações" segue na esteira das análises feitas, no pós-guerra, sobre a importância da 
educação, principalmente a superior, para o desenvolvimento econômico. Fazia-se necessário impulsionar a formação de mão-de-obra de alto nível, dotando o país de contingentes de pessoas bem treinadas que pudessem assumir a condução do processo de desenvolvimento. Apesar de terem sido o Plano de Metas de Juscelino Kubitschek - o Meta 30, em 1956 e o Plano Trienal de Celso Furtado, em 1962, os primeiros a incluir considerações sobre a importância da formação de recursos humanos para o desenvolvimento, desde o fim da $2^{\text {a }}$ Guerra Mundial já se vinham construindo as bases da Teoria do Capital Humano que, posteriormente, orientaria as ações do Ponto IV (1948), de seu Projeto ETA-55 (1955) e dos planos de desenvolvimento geral e setorial que o governo proporia. Portanto, a partir de 1950, várias escolas superiores e universidades são federalizadas. As Leis $\mathrm{n}^{0} 1.055$, de 16 de janeiro, e $\mathrm{n}^{0} 1.254$, de 4 de dezembro, ambas de 1950, federalizam várias universidades, escolas e faculdades, dentre elas, diversas de Agronomia e Veterinária. Em 1955, das instituições de ensino agrícola superior, apenas uma era particular, a de Lavras, e seis eram estaduais: as Escolas Superiores de Agricultura e Veterinária da UREMG; a Faculdade de Medicina Veterinária e a Escola Superior de Agricultura Luiz de Queiroz, da USP; e as escolas isoladas de Agronomia, em Cruz das Almas, e Veterinária da Bahia, em Salvador. Todas, porém, eram subvencionadas pelo governo federal. As demais pertenciam à União e eram por ela mantidas.

A tomada de consciência da necessidade de se formarem recursos humanos para que o país pudesse desenvolver-se manifestou-se, na década de 20, pelo movimento da Escola Nova; na década de 30, pela Reforma Francisco Campos, do Estatuto das Universidades Brasileiras e pelas reformas da legislação sobre o ensino superior agrícola; na década de 40, promulgaram-se as leis orgânicas do ensino comercial, industrial e agrícola, e criou-se o Senai; e, na década de 50, o Plano de Metas do governo Juscelino Kubitschek (1956-1960) explicitou, na Meta $n^{0} 30$, a integração da educação ao projeto de desenvolvimento, pela formação dos técnicos a ele necessários. 
Segundo Rodrigues (1948, p. 14), o modelo pós-1930 e, principalmente, o pós-1937 implicam

que a escola deverá exercer o papel preponderante, em nível de superestrutura, formando quadros superiores não apenas para o controle da produção e direção das consciências, mas igualmente para o aumento da produtividade, para a invenção técnica, para a comercialização, etc. A escola deve atuar diretamente no processo de acumulação de capital, à medida que, por sua ação educacional, amplia a produção das condições de reprodução do mesmo (p. 11).

Ainda segundo Rodrigues, o Plano de Metas de Juscelino Kubitschek "atribui tarefa importante à educação na formação dos quadros técnicos necessários ao sucesso do próprio Plano de Metas", (p. 11). Observa-se, no entanto, que além das "federalizações", outras medidas não foram tomadas na área agrária. Nenhum curso, por exemplo, foi criado entre 1952 e 1960. Além disto, se em 1932 havia 16 cursos de Agronomia e nove de Veterinária (MES/DE, 1939), em 1961 só havia 12 cursos de Agronomia (menos quatro) e oito de Veterinária (menos um). A avalanche de novos cursos só virá iniciar-se em 1961, para atingir seu ápice na década de 70 (Figuras 1 e 2). O que ocorreu de mais importante na área agrária, na década de 50, em verdade, foram as "federalizações" de escolas e universidades, as quais continuaram na década de 60 e significaram, por algum tempo, melhores condições físicas, financeiras e de pessoal para as instituições federalizadas. Essas "federalizações", no entanto, não são suficientes para justificar a afirmação de que a área das ciências agrárias estava sendo aparelhada ou colocada em movimento para garantir a formação dos recursos humanos necessários ao processo de acumulação do capital, naquele momento. Lima, Rodrigues, Cunha e outros (1961), que realizaram uma pesquisa sobre a situação das escolas de Agronomia e Veterinária em 1958, por exemplo, lamentavam o baixo salário dos professores e funcionários; a inadaptação e a inércia dos cur-

R. bras. Est. pedag., Brasília, v.72, n.172, p.229-261, set./dez.1991 
rículos; a pouca ênfase dada à pesquisa, bem como a sua raridade, e outros descuidos e debilidades mais das instituições de ensino superior agrícola. Diante da situação dos cursos de Agronomia e Veterinária, os autores chegaram a sugerir que se impedisse a abertura de novos cursos e que se aproveitasse a capacidade ociosa das instituições então existentes, oferecendo-se melhores salários aos professores e condições para que trabalhassem em regime de tempo integral, a fim de que se desenvolvesse a pesquisa (os regimes de trabalho dos professores eram, predominantemente, o de tempo parcial e o de remuneração por hora-aula). De outro lado, o número de matrículas era baixo, pois muitas vagas não eram preenchidas. Segundo, ainda, os autores, a taxa média de aproveitamento das vagas, em 1959, nas 12 escolas de Agronomia do país, foi de $68 \%$, e a das oito escolas de Veterinária foi de 56\% (p. 77). Em 1959, havia apenas 1.767 alunos nas escolas de Agronomia e 775 nas escolas de Veterinária (p. 80 e 88). Se intenção houve, então, do Estado, em colocar o ensino superior, a partir de 1930, a serviço da acumulação do capital, como afirma Rodrigues (1984), sua ação, na área agrária, foi inepta, insuficiente e contraditória, o que é estranho, pois o Estado é sempre considerado um eficiente fautor desses interesses. O mais provável, portanto, é que o ensino agrícola, da mesma forma que em seus primórdios, continuava, na década de 50, a ser tratado como algo de importância apenas residual, um investimento de lento, limitado e incerto retorno.

\section{E de 1960 para cá?}

O regime de posse da terra, no Brasil, caracteriza-se pela grande concentração fundiária. O Censo Agrícola de 1960 indicava que somente $31 \%$ do território nacional estava ocupado, registrando 3.350 .000 propriedades dos mais diversos tipos. A população rural era de cerca de 38 milhões de habitantes. O latifúndio de mais de mil hectares de área representava $0,9 \%$ das propriedades, mas ocupava $47,3 \%$ do total das terras. A atividade predominante era o latifúndio pecuarista. As propriedades de me- 
nos de 100 hectares representavam 44,6\% das propriedades e ocupavam apenas $17,9 \%$ da área total. Historicamente, a produção agrícola vinha crescendo menos que a população $(2,0 \%$ contra $3,5 \%$ ao ano). Os problemas do abastecimento dos grandes centros urbanos se agravava, o que era considerado um empecilho para o desenvolvimento do país, nos moldes capitalistas. As relações de produção, no campo, não sendo capitalistas (a não-difusão do trabalho assalariado, por exemplo), inviabilizavam o campo como mercado consumidor dos bens industrializados. Daí a necessidade urgente de se modificarem as condições do campo, para que o capitalismo pudesse realizar-se plenamente. No entanto, $34,5 \%$ dos estabelecimentos agrícolas recenseados em 1950 tinham área inferior a 10 hectares (minifúndios) e, por isso, sua renda era muito pequena, revelando enorme dificuldade em reunir tecnologias adequadas e produtividade. Eram estas propriedades improdutivas que concentravam a população rural, enquanto os latifúndios de mais de mil hectares estavam ociosos. Em 1965, mediante a Lei $\mathrm{n}^{\circ}$ 4.504, de 30 de janeiro de 1964, aprovava-se o Estatuto da Terra, que pretendia uma gradual extinção do minifúndio e do latifúndio. Ao mesmo tempo, passou-se a estimular a formação de agrônomos e veterinários e seu aperfeiçoamento profissional em níveis de mestrado e doutorado. Criaram-se "institutos" de Economia Rural e outros para que pesquisassem e apresentassem soluções para os problemas rurais. A agricultura brasileira entrava, dessa maneira, na terceira fase de sua evolução, segundo Alves (1974). Abandonava-se a crença de que todos os conhecimentos necessários ao desenvolvimento agrícola estavam disponíveis, bastando transferi-los aos agricultores. Percebeu-se que os conhecimentos existentes não eram suficientes. Urgia intensificar tanto a formação de profissionais quanto a produção de conhecimentos. As instituições de ensino, no entanto, ao serem convocadas para formar os profissionais agrícolas de nível superior, e para produzir os novos conhecimentos que se faziam necessários ao desenvolvimento, optaram pela formação de profissionais e pela produção de conhecimentos que interessassem principalmente aos latifundiários e não aos pe- 
quenos e médios agricultores; dessa maneira, estariam concorrendo para a instalação do modo de produção capitalista, no campo. Essas instituições não estariam produzindo nem os profissionais nem os conhecimentos que interessam ao pequeno agricultor, à pequena empresa agrícola. $\mathrm{O}$ ensino $\mathrm{e}$ a pesquisa estariam orientados para os problemas da grande empresa agrícola, para a grande cultura, para o grande capital. É por isto que não estão disponíveis tecnologias aplicáveis às pequenas empresas rurais, as quais funcionam, em geral, em regime de policul-tura de produtos de subsistência. Segundo alguns líderes da classe agronômica, o surgimento da figura do especialista, principalmente do zootecnista e do engenheiro agrícola, explica-se pela ideologia capitalista que dominaria o Ministério da Educação e a maior parte das instituições de ensino agrícola superior, levando-as a produzir profissionais que só interessam ao grande produtor rural, dado que o pequeno produtor não tem condições de contratar esse tipo de profissional nem de adotar os refinados conhecimentos e tecnologias de que, eventualmente, ele seja possuidor. As instituições de ensino e pesquisa agrícola estariam, desse modo, a serviço do capital, do latifúndio e das multinacionais produtoras de insumos agrícolas de alta tecnologia. Por isso, fazem-se necessárias propostas alternativas de formação profissionai e de cultivo da terra.

$\mathrm{Na}$ década de 50, ao mesmo tempo em que se davam as "federalizações", que continuaram na década de 60 e significaram o início de efetiva participação do governo federal no ensino superior agrícola, várias outras instituições passaram a se preocupar com o ensino e a pesquisa agrícolas. O Ponto $I V$ (Brasil/Usaid, Projeto ETA-55), o IICAOEA, a FAO, o BID e as Fundações Ford e Rockfeller, por exemplo, desempenharam um importante papel no surgimento da pós-graduação, na criação das novas carreiras profissionais, no treinamento de profissionais e professores, no exterior, no equipamento e construção de laboratórios e bibliotecas, e em outros setores mais. A partir do final da década de 50, houve importante concentração de esforços e de recursos para impulsionar o ensino superior e a pesquisa agrícola. 
Quanto à extensão rural, deste 1948 vinha-se desenvolvendo, com a cooperação dos Estados Unidos da América, uma importante experiência em Minas gerais - a Associação de Crédito e Assistência Rural (ACAR), que mais tarde se espalhou por todo o Brasil, por meio da Associação Brasileira de Crédito e Assistência Rural (ABCAR), a qual, em 1973, foi reestruturada e recebeu o nome de Empresa Brasileira de Assistência Técnica e Extensão Rural (Embrater). A extensão rural foi a maior em-pregadora de profissionais agrícolas de nível superior, durante muitos anos. Por isso, grande número de cursos, principalmente de Agronomia, orientaram seus currículos e seus programas para a formação de "extensionistas".

Quanto à pesquisa agrícola, esta se desenvolveu desde cedo nas instituições de ensino superior agrícola. A própria natureza dos temas agrícolas favorece o desenvolvimento da pesquisa, paralelamente ao ensino. Importante, por exemplo, foi a contribuição do Centro Nacional de Ensino e Pesquisa Agronômicas (CNEPA), criado em 1938, por meio do Decreto-Lei $\mathrm{n}^{0}$ 892, de 23 de dezembro de 1938. No entanto, foi a criação dos cursos de pós-graduação em sentido estrito (mestrado e doutorado), a partir de 1960, que imprimiu especial alento à pesquisa agrícola no Brasil. Grande esforço também foi feito para se formar recursos humanos para a pesquisa, mediante cursos de pós-graduação no exterior, com o apoio de bolsas de estudo concedidas pelas seguintes instituições: Usaid, Fundação Ford, Fundação Rockfeller, OEA, FAO, CNPq e CAPES. A pesquisa agrícola recebeu um impulso muito forte com a criação da Empresa Brasileira de Pesquisa Agropecuária (Embrapa), em 1972 (apesar de esta instituição concorrer com as universidades pelos mesmos recursos minguados para a pesquisa). Além de contratar muitos profissionais agrícolas de nível superior, a Embrapa montou um importante programa de treinamento de pós-graduação para o seu pessoal, no país e no exterior, com recursos do Banco Mundial e a cooperação da CAPES/MEC.

Se em determinado instante, no começo da década de 60, acreditou-se que para viabilizar o capitalismo industrial no Brasil 
seria necessária a reforma agrária, para transformar a agricultura no suporte confiável necessário à industrialização, em um segundo momento descartou-se a reforma agrária e optou-se por intensificar a penetração do capitalismo na agricultura (Linhares e Silva, 1979, p. 130), aplicando-se nela os mais modernos resultados da pesquisa e da tecnologia agrícola. Para isto, faz-se necessário formar a mão-de-obra especializada que viabilizasse o projeto.

O ensino agrícola de nível superior conheceu, a partir da década de 60, um vertiginoso crescimento (Gráficos 1 e 2): iniciou-se a pósgraduação, no nível de mestrado; criaram-se novas carreiras profissionais; multiplicaram-se os cursos e as vagas. Comparando-se o crescimento do ensino superior agrícola com o crescimento das demais áreas, constata-se que ele chegou a ser espetacular, coincidindo os momentos de seus mais importantes avanços com os anos do "milagre econômico". A pósgraduação na área. é considerada uma das mais adiantadas, e a pesquisa por ela produzida tem nível internacional.

Todo empenho do governo brasileiro e das agências internacionais, a partir de 1960, para o desenvolvimento das "ciências agrárias", no Brasil, pode ser considerado como tendo atingido completo êxito. No entanto, muitos profissionais da área se indagam sobre a quem está interessando todo esse êxito. Tem-se constatado que os bons resultados do ensino, da pesquisa e da assistência técnica vêm sendo apropriados pelo grande capital nacional e internacional; que existe um processo contínuo e crescente de concentração da renda e da propriedade rural, que não consulta aos interesses do povo brasileiro, principalmente daquelas parcelas da população que vivem no campo e do campo. Estes temas têm sido discutidos em congressos das associações de estudantes e das entidades profissionais. Em reuniões dessa natureza, como é compreensível, apresentam-se tanto os discursos entusiasmados e "deslumbrados", que não têm compromissos com os resultados das pesquisas e que propõem soluções utópicas, completamente alheias à realidade e "enfurecidamente" contrárias a tudo que aí está, quanto posições mais serenas, que per- 


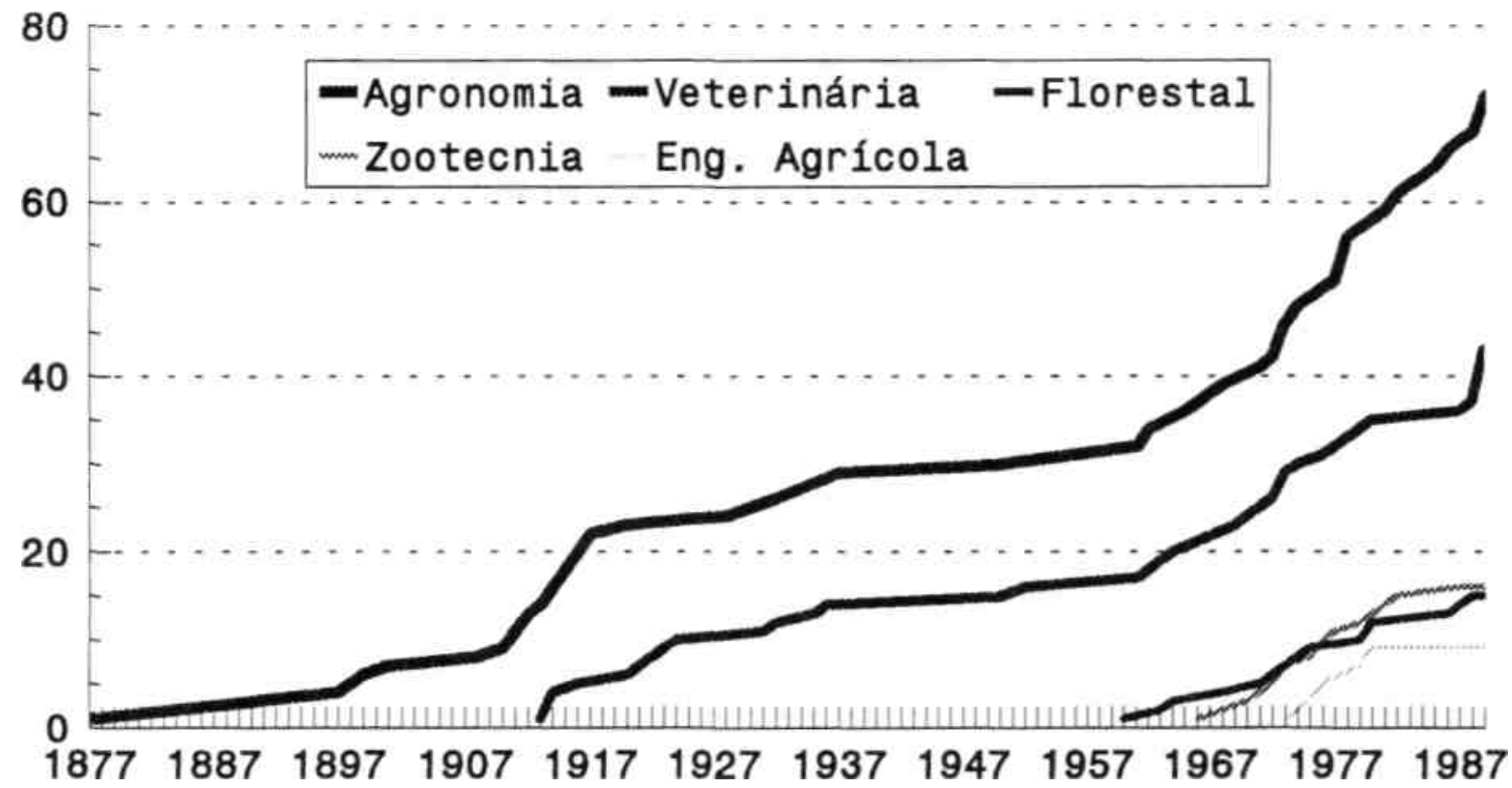

Gráfico 1 - Evolução dos cursos de Engenharia Agronômica Veterinária, Engenharia Florestal, Zootecnia e Engenharia A Brasil, entre 1877 e 1989. (Cursos criados) 


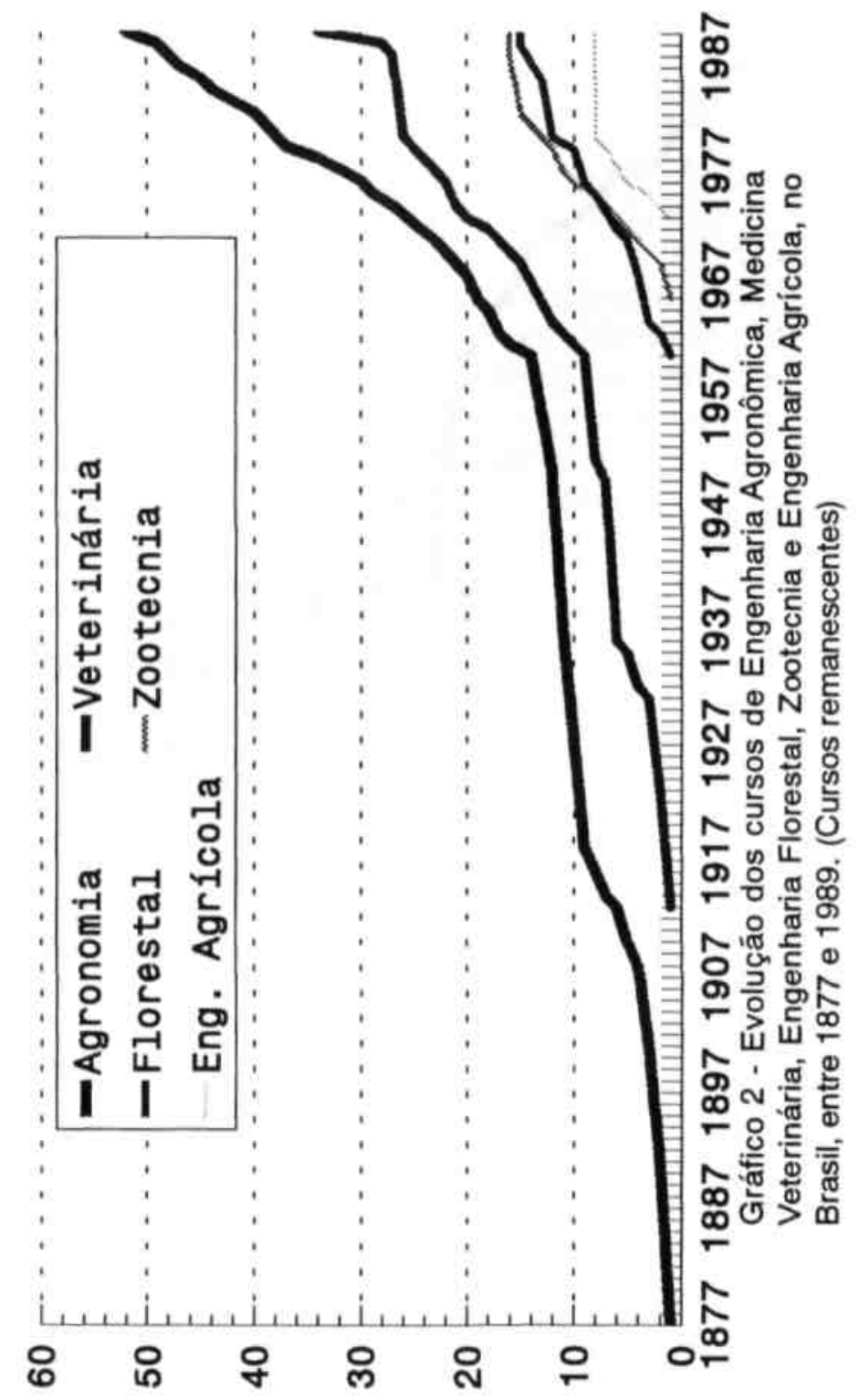


cebem ser impossível que a maioria dos profissionais, professores e estudantes sejam pessoas "vendidas" a interesses estranhos à Nação. No entanto, essas questões têm freqüentado cada vez mais a lista de preocupações dos estudantes e profissionais da área, como revelam os programas de seus congressos e encontros.

De outro lado, a crise econômica em que se debate o país tem trazido consigo uma violenta diminuição das oportunidades de emprego, pegando na contramão todo aquele contingente de jovens que, acreditando na importância econômica das atividades agropastoris, tinham optado, há algum tempo, por uma carreira agrícola de nível superior. Ao chegarem ao mercado de trabalho, eles têm enfrentado sérios problemas de emprego. Por essa razão, percebe-se uma queda na demanda de vagas, nos vestibulares, por essas carreiras, a qual, no entanto, não é muito maior que a das demais áreas. As associações profissionais, por seu lado, vêm tentando impedir a abertura de novos cursos na área, mas as medidas que vêm tomando têm-se revelado ineficazes. $\mathrm{O}$ crescente número de jovens que concluem o segundo grau vem motivando políticos e empresários do ensino a abrir cursos que possam absorvê-los, com os olhos em ganhos eleitorais e/ou financeiros. Aproveitando-se das brechas da legislação vigente, ou contornando seus empecilhos, vêm-se abrindo muitos cursos pelo país afora, os quais não ostentam as mínimas condições de funcionamento, mas acabam por colocar as autoridades educacionais diante de fatos consumados. O Ministério da Educação e até a Presidência da República têm sido pressionados no sentido de coibir esses "abusos" e proibir a abertura de novos cursos dessa espécie. No entanto, não há como o governo federal controlar os governos estaduais e municipais em área que é de suas respectivas competências. As entidades profissionais, no entanto, embora tenham conhecimento disto, continuam insistindo em transferir para o governo federal o ônus da luta inglória de controlar a abertura de novos cursos, ao invés de enfrentarem, elas mesmas, diretamente, in loco, com seus recursos de pressão, os riscos de desprestígios e desgaste político que significaria uma 
campanha para impedir a abertura deste ou daquele curso, nesta ou naquela localidade.

De 1877 até 1960 (em 83 anos) funcionaram, no Brasil, 30 cursos de Agronomia, 18 dos quais foram extintos. De 1961 a 1989 (em 27 anos), criaram-se, no país, 43 novos cursos de Agronomia e apenas um foi desativado. De 1913 (ano da criação do primeiro) a 1960 (em 47 anos) funcionaram, no Brasil, 16 cursos de Medicina Veterinária, 8 dos quais foram extintos. De 1961 a 1989 (em 28 anos), criaram-se, no país, 27 novos cursos, dos quais apenas um foi desativado. A partir de 1960, foram também criados 15 cursos de Engenharia Florestal, 16 de Zootecnia e 8 de Engenharia Agrícola. Todo esse espetacular florescimento ocorrido a partir da década de 60 reflete o enorme interesse despertado pela área agrária e a importância por ela assumida diante do governo.

Se a educação como um todo e a educação superior em particular passaram a merecer especial atenção do governo após 1960, o que ocorreu com a educação agrícola superior foi mais importante ainda. Considerado ensino de segunda classe e continuando apenso ao Ministério da Agricultura até 1967, o ensino superior agrícola passou a demonstrar, a partir da década de 60, uma admirável vitalidade, crescendo agressivamente, inaugurando a pós-graduação em sentido estrito (mestrado e doutorado), no Brasil (Capdeville, 1989), e ostentando um dos mais altos índices de pessoal docente altamente qualificado (Castro e Spagnolo, 1982). Seus cursos de pós-graduação e sua produção científica alcançaram nível internacional e a aplicação dos resultados de sua pesquisa tem dado significativo retorno (Idem, ibidem). De modo algum a agricultura brasileira teria atingido seus níveis atuais, concorrendo, como tem feito, para a obtenção dos atuais excedentes comerciais de nossa balança comercial, não fosse a qualidade do ensino superior agrícola, graduado e pós-graduado, e de sua produção científica.

Faz-se, agora, necessário realizar-se uma avaliação tanto dos rumos que vem tomando o ensino superior agrícola quanto de seus resultados. Na condição de área que possui proporcionalmen- 
te um dos maiores elencos, senão o maior, de profissionais altamente qualificados (M.S. e Ph.D.), no país, o ensino superior agrícola precisa, com os recursos da ciência, voltar-se sobre si mesmo, e realizar um minucioso levantamento de sua atual situação, para, em seguida, submetêla a um vigoroso exame crítico. Dessa maneira se exorcizariam duas ameaças igualmente sinistras que - soe acontecer - sempre rondam as empresas bem sucedidas: de um lado, a inércia provocada pelo narcisismo das autocon-templações muito generosas e, de outro, a autodestruição do "ôba-ôba" reformista e da crítica inconseqüente e, por isso, irresponsável.

\section{Referências bibliográficas}

ALVES, Eliseu R. A Embrapa e a pesquisa no Brasil. [S.l.:s.n.], 1974. (Embrapa documentos, 2).

ASSOCIAÇÃO BRASILEIRA DE EDUCAÇÃO AGRÍCOLA SUPERIOR. Guia das instituições de ensino superior de Ciências Agrárias: graduação e pós-graduação. 4.ed. Brasília, 1989.

BRASIL. Ministério da Educação e Saúde. Diretoria de Estatística. $O$ ensino no Brasil ano I, 1932. Rio de Janeiro: Imprensa Nacional, 1939.

CAPDEVILLE, Guy. A formação do profissional agrícola de nível superior no Brasil. Rio de Janeiro, 1989. Tese (Doutorado) Universidade Federal do Rio de Janeiro.

CASTRO, Cláudio de M., SPAGNOLO, Fernando. Science and scientists in agriculture: the Brazilian case. In: IASEI. Tercer Seminário Internacional de Investigación Educativa. Jalisco: Ajüc, 1982. mimeo.

CRESPO, João Py. Relatório apresentado ao Exm ${ }^{0}$ Sr. Ministro da Agricultura pelo Diretor do Lyceu Rio-grandense de Agronomia e Veterinária de Pelotas. Pelotas: Imprensa a Vapor, Liv. Universal de Echenique \& Irmão, 1894.

R. bras. Est. pedag., Brasília, v.72, n.172, p.229-261, set./dez. 1991 
FREITAG, Barbara. Escola, estado e sociedade. São Paulo: Moraes, 1986.

LIMA, J.P., RODRIGUES, L.M., CUNHA, T.F. da et al. Técnicos para o desenvolvimento da agricultura. Rio de Janeiro: ABGAR: IBGE, 1961.

LINHARES, Maria Y.L., SILVA, F.C

.T. da. História política do abastecimento (1918-1974). Brasília: Binagri, 1979.

RODRIGUES, Neidson. Estado, educação e desenvolvimento econômico. São Paulo: Autores Associados: Cortez, 1984.

SOARES, Sebastião F. Notas estatísticas sobre a produção agrícola e carestia dos gêneros alimentícios no Império do Brasil. Rio de Janeiro: IPEA, INPES, 1977.

Recebido em 28 de março de 1991

Guy Capdeville, doutor em Educação pela Universidade Federal do Rio de Janeiro (UFRJ), é professor aposentado da Universidade Federal de Viçosa (UFV).

In february 15th, 1877, the first agrarian science high levei Course has been settled in Brazil, namely, the Agronomy Course at the Imperial Escola Agricola da Bahia, Since then till 1910 - when the first official regulamentation of this kind of instruction was done - eight agronomy courses have been functioning in the country. Although the school's (Imperial Escola Agricola da Bahia) statute (established in 1875) foresaw int its 5th article, besides the agronomy course, also the high levei courses of agricultural engineering, orestation and veterinary science, the first Veterinary Medicin Course was opened in Rio de Janeiro, only in 1913. In 1960 was created the first Forest Engineering course in Viçosa-MG; the first Zootechny Course in 1966 (Uruguaiana-RS) and in 1973, the first Agricultural Engineering Course (Pelotas). In january, 1990, there were 72 Agronomy courses; 43 Veterinary courses; 14 Forest Engineering courses; 16 Zootechny courses and 9 Agricultural 
Engineering courses. The first brazilian post-graduation course related to agrarian sciences (the north-american "Master of Science" standard or "Magister Scientiae"), was opened at the Minas Gerais Rural University, today named Universidade Federal de Viçosa, in march 1951. In january 1990, there were 108 MS courses and 18 PhD courses linked to agrarian sciences in Brasil. Nowadays it's common sense that the high levei agrarian Professional instruction is one of the most successful áreas from the brazilian educational system.

L'article presente l'histoire du surgissement et l'évolution de l'enseignement Superieur agricole au Brésil. Le 15 février 1877 commençait au Brésil le premier cours Supérieur au domaine des sciences agraires, le cours de Agronomia da Imperial Escola Agrícola da Bahia. Dépuis ce jour jusqu'à 1910 l'année de la première réglementation officielle de ce type denseignemment — ont fonctionné au Brésil huit cours d'Agronomie. Même que les statuts de la Imperial Escola Agrícola da Bahia (1875), dans l'article 5 ème, prévoyaient, autre le cours d'Agronomie, ceux d'Ingénieur Agricole, Sylviculture et Vétérinaire, le premier cours de Médicine Vétérinaire a commencé seulement le 1913, à Rio de Janeiro. Se 1960, on a crée le premier cours d'Ingénieur Forestier (Viçosa-MG); le 1966, le premier de Zootechnie (Uruguaiana-RS) et, le 1973, le premier d'Ingénieur Agricole (Pelotas-RS). Se janvier 1990, les cours d'Agronomie étaient 72; ceux de Vétérinaire, 43; ceux d'Inglénieur Forestier, 14, ceux de Zootechnie, 16 et ceux d'Ingénieur Agricole, 8. Se mars 1961 a été inaugure à l'Université Rurale de l'Etat de Minas Gerais, aujourd'hui Université Fédérale de Viçosa, le premier cours de postgrade, au Brésil, selon le modele nord-américain du Master of Science ou Magister Scientiae. Se janvier 1990, il y avait 100 cours de maêtrise et 28 de doctorat en Sciences Agraires au Brésil. On Croit que la formation de professionels agricoles au niveau supérieus est un des domaines bien réussits dans L'éducation brésilienne.

Historia surgimiento y evolución de la enseñanza agrícola en el Brasil. El 15 de febrero de 1877, se instaló en el Brasil, el primer curso superior del área de ciências agrícolas - el curso de Agronomia de la Imperial Escuela Agricola de Bahia. Desde esa fecha hasta 1910

R. bras. Est. pedag., Brasília, v.72, n.172, p.229-261, set./dez. 1991 
— año en que se hizo la primera reglamentación oficial de ese tipo de ensenanza - funcionaran, en el Brasil, ocho cursos de agronomia. Aunque los estatutos de la Imperial Escuela Agrícola de Bahia (1875) preveyesen, en su artículo $n .5$, además del curso de Agronomia, los cursos superiores de Ingeniería Agricola, Silvicutura y Veterinaria. El primer curso de Medicina Veterinaria solo fue inaugurado en 1913, en Rio de Janeiro. En 1960, se creo el primer curso de Ingeniería Florestal (Viçosa-MG); en 1966, el primem de Zootecnia (Uruguaiana-RS) y, en 1973 el primero de Ingeniería Agrícola (Pelotas-RS). En enero de 1990, los cursos de Agronomia eran 72; los de Veterinária 43; los de Ingeniería Florestal, 14; los de Zootecnia, 16; y los de Ingeniería Agricola, 8. En marzo de 1961, se inauguro, en la entonces Universidad Rural del Estado de Minas Gerais, hoy la Universidad Federal de Viçosa, el primer curso de Postgraduación, en el Brasil, basado en el modelo norteamericano de "Master of Science", o "Magister Scientiae". En enero de 1990, había 108 cursos de maestria y 28 de doctorado en Ciencias Agrarias en el Brasil. Se cree que la formación de profesionales agrícolas de nível superior es una de Ias áreas más exitosas de la educación brasileña. 


\section{Anexo 1}

Cursos de Engenharia Agronômica que funcionaram no Brasil entre 1877 e 1989

1877 - UFBA - Cruz das Almas-BA 1891 -

UFPEL - Pelotas-RS 1891 - (extinto) -

Taquary-RS

1897 - (extinto) - Porto Alegre-RS

1898 - (extinto) - Politécnica-SP

1899 - (extinto) - Politécnica-RJ 1901 -

ESALQ/USP - Piracicaba-SP 1908 - ESAL -

Lavras-MG

1910 - UFRGS - Porto Alegre-RS

1911 - (extinto) - Salvador-BA

1911 - (extinto) - Jaboatão-PE

1912 - (extinto) - Manaus-AM

1912 - (extinto) - Pinheiros-RJ

1913 - UFRRJ - Rio de Janeiro-RJ

1914 - UFRPE - Recife-PE

1914 - (extinto) - Belo Horizonte-MG

1915 - (extinto) - Paraná-PR

1915 - (extinto) - Cachoeira do Campo-MG

1918 - (extinto) - Passa Quatro-MG

1918 - UFPR - Curitiba-PR

1918 - UFCE - Fortaleza-CE

1918 - (extinto) - Belém-PA

1921 - (extinto) - Recife-PE

1928 - UFV - Viçosa-MG

1930 - (extinto) - Barreiros-PE

1932 - (extinto) - São Luís-MA

1935 - (extinto) - Niterói-RJ

1936 - (extinto) - Campos-RJ

1937 - UFPB - Areia-PB 1951

- FCAP - Belém-PA

R. bras. Est. pedag., Brasília, v.72, n.172, p.229-261, set./dez. 1991 


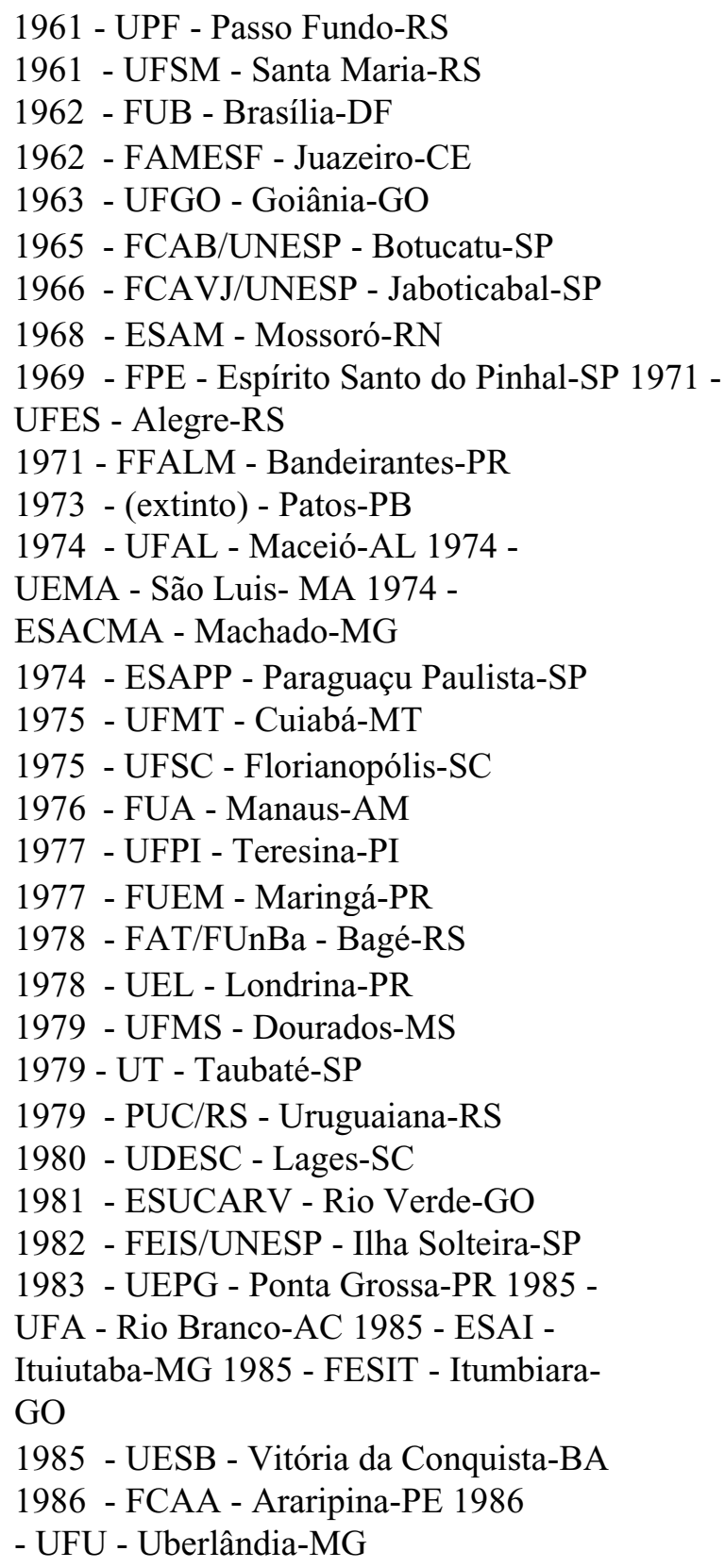



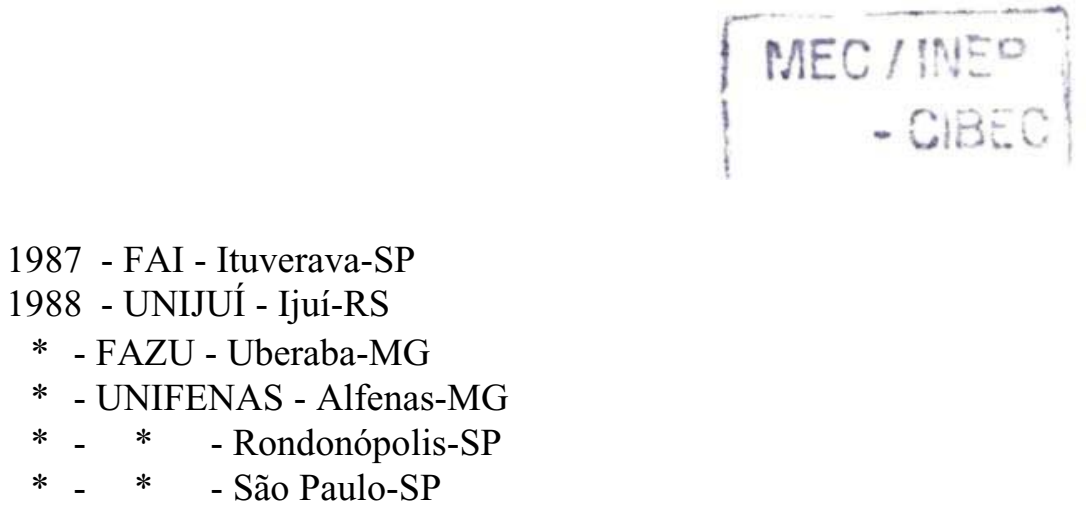

(*) Informação não disponível.

Fontes: 1. Arquivo morto do Ministério da Educação, 1988.

2. Guia das Instituições de Ensino Superior de Ciências Agrárias: graduação e pós-graduação. 4.ed. Brasília: ABEAS, 1989. 


\section{Anexo 2}

\section{Cursos de Medicina Veterinária que funcionaram no Brasil entre 1913 e 1988}

1913 - UFRRJ - Rio de Janeiro-RJ

1914 - (extinto) - Recife-PE

1914 - (extinto) - Rio de Janeiro-RJ 1914 -

(extinto) - Belo Horizonte-MG 1917 -

(extinto) - Pouso Alegre-MG 1920 - (extinto)

- São Paulo-SP

1922 - (extinto) - Passa Quatro-MG

1923 - UFRGS - Porto Alegre-RS

1924 - (extinto) - Juiz de Fora-MG

1925 - (extinto) - Belém-PA

1931 - UFPR - Curitiba-PR

1932 - UFMG - Belo Horizonte-MG

1935 - PVZ/USP - São Paulo-SP

1936 - IFF - Niterói-RJ 1950 - UFRPE

- Recife-PE 1952 - UFBA - Salvador-

BA 1961 - UFSM - Santa Maria-RS

1963 - UECE - Fortaleza-CE

1963 - FCAB/UNESP - Botucatu-SP

1964 - UFGO - Goiânia-GO 1969 -

UEMA - São Luiz-MA 1969 - UFPEL -

Pelotas-RS 1969 - PUC/RS -

Uruguaiana-RS 1971 - UFMS - Campo

Grande-MS

1971 - FCAB/UNESP - Jaboticabal-SP

1972 - UFU - Uberlândia-MG

1973 - UEL - Londrina-PR

1973 - UDESC - Lages-SC

1973 - (absorvido) - Patos-PB

1974 - FCAP -Belém-PA 


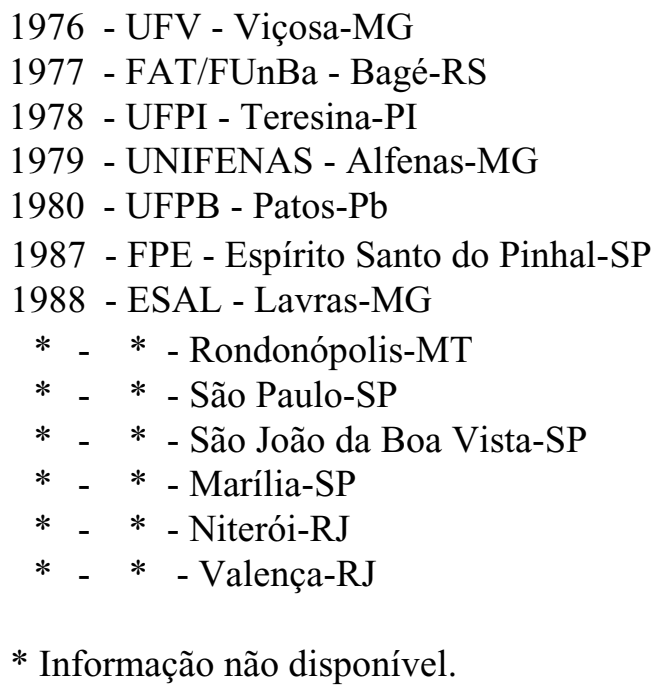

Fontes: 1. Arquivo morto do Ministério da Educação, 1988.

2. Guia das Instituições de Ensino Superior de Ciências Agrárias: graduação e pós-graduação. 4.ed. Brasília: ABEAS, 1989. 